\title{
A RESPONSABILIDADE CIVIL E O MEIO AMBIENTE
}

\section{THE CIVIL RESPONSIBILITY AND ENVIRONMENT}

\author{
DelCylene VilLaLba Soares \\ Acadêmica do Curso de Direito da Universidade da Região da Campanha (URCAMP), \\ Campus Universitário de Sant'Ana do Livramento. \\ lenesoares.22@hotmail.com
}

\begin{abstract}
RESUMO
Este artigo tem por finalidade realizar uma análise sobre a evolução da responsabilidade civil e suas teorias, subjetiva e objetiva aplicadas ao meio ambiente. Dentro desta área, deve-se ressaltar que a responsabilidade civil ao meio ambiente, é um assunto de importante relevância para o efetivo controle da depredação ambiental, permitindo que sejam alcançadas as metas propostas como condição de sobrevivência da espécie humana, ou seja, a conservação do meio ambiente e o desenvolvimento econômico social, visando desta maneira, permitir a qualidade e a continuação da vida. Existe o entendimento, que somente com educação ambiental e normas reguladoras fortes, como a penalidade de ter que indenizar quando praticar algum dano ao meio ambiente conseguirá atingir o objetivo maior de preservação. Necessitam-se além de uma mudança na legislação que responsabilize poluidores do meio ambiente, atribuindo-lhes sanções que inibam a prática de tal conduta ilícita e realizando assim, a aplicabilidade da justiça.
\end{abstract}

Palavras-chave:

Responsabilidade Civil; Responsabilidade; Meio Ambiente

\begin{abstract}
This article have objective to realize a analysis about civil responsibility evolution and your theories, subjective and objective apply environment. Inside this area have to stand out that civil responsibility environment, it is a theme very important relevance for environment depredation control effective, permitting have been obtain proposals target like been human survival condition, therefore, environment conservation and social economic development objective permit quality and continuation of life. There is understanding, that only with environment education and strong regulation principle, like penalty has to indemnify when practice some injury of environment, will obtain more preservation. Demand a change on legislation that responsible environment polluter attribute him inhibit sanctions for practice this illicit conduct and realize applicability of justice.
\end{abstract}

Keywords:

Civil Responsibility; Responsibility; Environment

\section{SUMÁRIO}

INTRODUÇAO; 1 RESPONSABILIDADE CIVIL. 2 TEORIA OBJETIVA E SUBJETIVA DA RESPONSABILIDADE CIVIL AMBIENTAL. 3 O MEIO AMBIENTE. 4 DANO E DANO AMBIENTAL CONCLUSÃO; REFERÊNCIAS. 


\section{INTRODUÇÃO}

O estudo da evolução e da história da Responsabilidade Civil se faz extremamente benéfico e necessário, pois, como diz José de Aguiar Dias": “Não foi possível até hoje, malgrado o esforço dos melhores juristas, estabelecer uma teoria unitária e permanente da responsabilidade civil”. Sua evolução é muito célere adaptando-se aos avanços tecnológicos, industriais e a todo processo evolutivo da sociedade, que assegurava restabelecer o equilíbrio desfeito por ocasião do mal sofrido, considerado, em cada tempo, em função das categorias sociais então vigentes.

A evolução da responsabilidade civil foi bastante branda, mesmo com a necessidade demonstrada e exigida pela sociedade em conquistar sua pretensão em obter compensação pelo prejuízo causado pelo outrem. Pode-se garantir, com extrema segurança, que a evolução apresentada como a justiça pelas próprias mãos, num primeiro momento histórico, até se chegar à aplicação efetiva desta pelo Estado, percorreu um longo trajeto. Se o capítulo da história da responsabilidade civil ressalva as questões abrangendo o surgimento dos primeiros conflitos de interesses e da solução encontrada para estes na primitiva e parcial justiça privada, resultante quando não muito na punição de todo um grupo social pelo crime de um de seus integrantes, a segunda fase desta evolução nos traz o Estado assumindo a atribuição de acalmar os ânimos e resolver as pretensões insatisfeitas.

Institucionalizando o caráter punitivo, cotidiano às primeiras civilizações, em detrimento ao instituto do ressarcimento, o Código de Hamurabi, constituído pelo célebre imperador babilônico, dois milênios antes da era cristã, consagrava o princípio do olho por olho, dente por dente, tempo depois, sacramentado pelos romanos. Rígida e inflexível, por muitas vezes cruel, a legislação de Hamurabi recepciona primeiramente uma noção de vingança delimitada pelo Estado, para só depois apresentar, ideias relacionadas às modernas indenizações, como nos dias de hoje são conhecidas por toda a nossa sociedade. Não existia naquela época uma distinção formal entre ilícito civil e criminal, na forma em que os regramentos da atualidade procuram classificar; não obstante sendo cultivada oficialmente pelo Estado, a sanção invariavelmente passava da pessoa responsável pelo crime ou dano, atingindo mesmo patrimônio e a própria vida de terceiros desvinculados das relações inter pars, fossem

${ }^{1}$ DIAS, José de Aguiar. Da Responsabilidade Civil. Rio de Janeiro: Forense, 2004. p. 25. 
elas privadas ou de fundo público, numa ação abominada integralmente pelos modernos ordenamentos jurídicos, com sua constitucionalidade concepção, no caso do Brasil e de outras pátrias, de que a pena não deve passar do condenado.

Um marco na evolução histórica da responsabilidade civil se dá, porém, com a implantação da Lex Aquiliana de damno, cuja importância foi imensa de tal forma que, deu nome à nova designação da responsabilidade civil delitual e extracontratual. Esta cristalizou um princípio geral que regula a reparação do dano, e foi constituído em três partes, não conseguindo revogar totalmente a legislação anterior, seu grande beneficio é propugnar pela substituição das multas fixas por uma pena adequada ao dano causado. Se seu primeiro capítulo ajustava o caso da morte dos escravos ou dos quadrúpedes que pastam em rebanho: e o segundo, o dano causado por um credor acessório ao principal, que pende a dívida com prejuízo do primeiro; sua terceira parte se tornou a mais importante para a compreensão da evolução da responsabilidade civil.

Com efeito, acondicionava o damnum injuria datum (dano produzido pela injúria), no qual, consiste na destruição ou deterioração da coisa alheia por fato ativo que tivesse acertado coisa corpórea, sem qualquer justificativa legal. Embora sua finalidade original fosse limitada ao próprio dono de coisa lesada, a influência da jurisprudência e as extensões concedidas pelo pretor fizeram com que se construísse uma doutrina romana essencial da responsabilidade extracontratual.

Admitindo-se um salto histórico, observa-se que a inserção da culpa como elemento fundamental da responsabilidade civil aquiliana, contra o objetivismo exagerado do direito primitivo, prescindindo a concepção de pena para substituí-la, paulatinamente, pela ideia de reparação do prejuízo sofrido, foi incorporado no colossal monumento legislativo da idade moderna, a saber, o Código Civil de Napoleão, que influenciou diversas legislações do mundo, inclusive o Código Civil Brasileiro de 1916 e também no Código Civil Brasileiro de 2002.

O Código Civil Brasileiro de 2002 adotou a teoria da culpa como princípio da responsabilidade civil, art. 186, onde constituiu o seguinte, in verbis: “Aquele que, por ação ou omissão voluntária, negligência ou imprudência, violar direito e causar dano a outrem, ainda que exclusivamente moral, comete ato ilícito". 


\section{RESPONSABILIDADE CIVIL}

A palavra responsabilidade origina-se do latim respondere que incide na ideia de ter alguém se constituído garantidor de algo. Tal termo contém, portanto, a raiz latina spondeo, fórmula pela qual, se atrelava, no direito romano, o dever nos contratos verbais. Diz-se que a responsabilidade e todas as suas expressões dão a ideia de uma contraprestação de correspondência.

Cretella $\mathrm{Jr}^{2}$, em suas palavras define o seguinte: “A responsabilidade civil decorre da ação ou omissão, dolosa ou culposa, cuja consequência seja a produção de um prejuízo”.

A responsabilidade civil, conforme Serpa Lopes ${ }^{3}$, "significa a obrigação de reparar um prejuízo, seja por decorrer de uma culpa ou de outra circunstância legal que a justifique, como a culpa presumida, ou por uma circunstância meramente objetiva”.

$\mathrm{Na}$ definição do conceituado Irineu Antônio Pedroti ${ }^{4}$ : “Na acepção jurídica responsabilidade corresponde ao dever de responder (do latim respondere) pelos atos próprios e de terceiros, sob proteção legal, e de reparar os danos que forem causados”.

Isso revelado muito ajuda no entendimento e conceituação do que é a responsabilidade civil.

Maria Helena Diniz ${ }^{5}$ asseverou o seguinte:

[...] A responsabilidade civil é a aplicação de medidas que obriguem uma pessoa a reparar dano moral ou patrimonial causado a terceiros, em razão de ato por ela mesma praticado, por pessoa por quem ela responde, por alguma coisa a ela pertencente ou de simples imposição legal.

O conceito de responsabilidade civil é bastante discutido entre os autores brasileiros na atualidade.

No aspecto "responsabilidade" pode existir tanto no plano jurídico como no moral. A responsabilidade Jurídica se cinde em responsabilidade civil e responsabilidade penal, exigindo a acentuação dos seus tipos diferenciais. A noção de responsabilidade, como maneira, implica sempre exame de comportamento voluntário violador de um dever jurídico. Sob tal permissa, a

2 JÚNIOR, José Cretella. O Estado e a Obrigação de Indenizar. São Paulo: Saraiva, 1980.p. 43.

${ }^{3}$ LOPES, Miguel Maria de Serpa. Curso de Direito Civil. v. 5. 2 ed. Rio de Janeiro: Freitas Bastos, 1995. p. 160.

${ }^{4}$ PEDROTI, Irineu Antônio. Responsabilidade Civil. 2. ed. São Paulo: Universidade de Direito, 1995. p.8.

${ }^{5}$ DINIZ, Maria Helena. Curso de Direito Civil Brasileiro: Responsabilidade Civil. v. 7, 21. ed. São Paulo: Saraiva, 2009. p.35. 
responsabilidade pode ser de várias naturezas, embora ontologicamente a apreciação seja a mesma.

De princípio há um divisor de águas entre a responsabilidade penal e civil. A ilicitude pode ser civil ou penal. Como a definição da conduta penal é sempre uma tipificação restrita, em princípio a responsabilidade penal ocasiona a obrigação de indenizar. Por essa razão, a sentença penal condenatória faz coisa julgada no cível quanto ao dever de indenizar o dano decorrente da conduta criminal, na forma dos artigos 91, I do Código Penal, 63 do Código de Processo Penal e 584, II do Código de Código de Processo Civil. As jurisdições penal e civil em nosso país são independentes, mas existem reflexos no juízo cível, não só sob o mencionado aspecto da sentença penal condenatória, como também porque não podemos discutir no cível a existência do fato e da autoria do ato ilícito, se essas questões foram definidas no juízo criminal e encontram-se sob o manto da coisa julgada (artigos 64 do Código de Processo Penal, 935 do atual Código Civil). De outra maneira, a sentença penal absolutória, por falta de provas quanto ao acontecimento, quanto à autoria, ou a quem reconhece uma dirimente ou justificativa, sem estabelecer a culpa, por exemplo, não tem influência na ação indenizatória que pode decidir autonomamente toda a matéria em seu bojo.

Como visto, o círculo dos atos ilícitos como casos e atos humanos é muito mais amplo: o ilícito civil nem sempre configurará uma conduta punível, descrita pela lei penal. Apesar disso, a ideia de transgressão de uma obrigação jurídica está presente em ambas as responsabilidades. Cabe ao legislador definir quando é oportuno e conveniente tornar a conduta criminalmente punível.

A responsabilidade penal abarca também um dano, dano que atinge a paz social, embora atinja muitas vezes um só indivíduo. Mas a ação repressiva não tem por objeto o dano causado ao particular, como tal, mas como integrante do grupo.

Se a responsabilidade civil pretende sobrepujar o dano privado, restabelecendo o equilíbrio individual perturbado, a responsabilidade penal tem a finalidade de restabelecer o equilíbrio social perturbado, averiguando antes da imputabilidade do agente e da antissocialidade civil.

\section{TEORIA OBJETIVA E SUBJETIVA DA RESPONSABILIDADE CIVIL AMBIENTAL}

Ao se analisar a teoria do risco, mais precisamente do chamado risco criado, nesta etapa de responsabilidade civil de pós-modernidade, o que se leva em potencialidade de 
acarretar danos; a atividade ou procedimento do agente que resulta por si só na exposição a um perigo, leva-se em conta a atividade do gerador do dano por sua natureza e pela natureza dos meios adotados. Na modalidade objetiva o devedor responde por ato lícito. Sua conduta não é adversa ao direito. Nada de diferente é ou seria jurídica ou moralmente exigível dele. Não obstante, arca com o ressarcimento dos danos sofridos pelo meio ambiente. A noção de responsabilidade por ilícito não tem sido naturalmente operada por parte da tecnologia jurídica, que resiste em aceitar a hipótese de imputação de obrigação quem faz exatamente o que deveria ter feito que não desobedeceu minimamente às leis em vigor.

$\mathrm{Na}$ responsabilidade objetiva, há, em princípio, pulverização do dever de ressarcir por um número amplo de pessoas. A tendência pressagiada é de que no contrato de seguro se encontrará a solução para a amplitude de indenização que se espera em prol da paz social.

A objetivação da responsabilidade permite, enfim, a abstração de qualquer juízo de valor na imputação da obrigação. O dever deve pagar a indenização não porque cometeu algo irregular, que merece punição. Nem poderá, por outro lado, exonerar-se por nada ter cometido de errado. Sua culpa é irrelevante para qualquer consequência: não constituí obrigação, nem a separa; não diminui ou aumenta, não está em jogo, em resumo, qualquer apreciação moral de sua conduta, mas somente sua aptidão econômica para socializar os gastos da atividade entre os beneficiados por ela.

A teoria da responsabilidade objetiva não pode, portanto, ser admitida como regra geral, mas somente nos acontecimentos contemplados em lei ou sob o novo aspecto enfocado pelo corrente Código. Levemos em conta, entretanto, que a responsabilidade civil é objeto vivo e dinâmico na jurisprudência.

Tem que haver nexo causal adequado entre a atividade do que causou o dano e a lesão. Essa teoria é conhecida como responsabilidade sem culpa.

Entretanto, vale mencionar, também, o que sobre a responsabilidade objetiva, diz ser também responsabilidade pelo risco (teoria do risco). Sobre a teoria objetiva da responsabilidade civil, no entanto, com o didático - e sistemático - esclarecimento de Antônio Lindbergh Montenegro ${ }^{6}$ :

[...] Há também os que preferem estabelecer distinção entre a responsabilidade objetiva, responsabilidade pelo risco, responsabilidade sem culpa. $\mathrm{Na}$ responsabilidade objetiva o fundamento da indenização decorreria da existência de um evento lesivo ligado ao agente por um nexo de causalidade.

\footnotetext{
${ }^{6}$ MONTENEGRO, Antônio Lindbergh. Responsabilidade Civil. 2.ed. Rio de Janeiro: Lumen Juris, 1996.p. 4.
} 
A responsabilidade pelo risco teria o seu suporte em um risco específico, de perigo geral, produzido pela atividade do homem, de tal sorte que incidiriam em seu campo de ação tão somente os riscos imprevisíveis ou excepcionais.

Para minimizar questões mais de ordem bizantina do que técnicojurídica, a doutrina passou a empregar o termo responsabilidade sem culpa para abarcar todas as hipóteses que escapassem da órbita da responsabilidade subjetiva.

Cabe ressaltar, que a teoria objetiva se baseia na causalidade extrínseca, desvalendo a intenção do agente, pois, aquele que obtém vantagens pelo risco criado, deverá responder pela consequência do ato praticado.

Já a Teoria da Responsabilidade Civil Subjetiva é atribuir a quem incorre em ilícito a obrigação de ressarcir os prejuízos decorrentes, a lei prestigia a noção de que a pretensão é a fonte de todas as obrigações.

Também conhecida como a teoria da culpa, a teoria subjetiva avalia a culpa como fundamento da responsabilidade civil, portanto, se não houver culpa, não existe responsabilidade. 0 doutrinador Sérgio Cavalieri ${ }^{7}$ abrange que:

[...] a ideia de culpa está visceralmente ligada à responsabilidade, por isso que, de regra, ninguém pode merecer censura ou juízo de reprovação sem que tenha faltado com o dever de cautela em seu agir.

Quem é culpado por ato ilícito é porque agiu como não deveria ter agido. Foi negligente naquilo em que deveria ser cauteloso, imperito quando tudo dependia de sua habilidade, imprudente se era exigida do causador cautela, ou comportou-se conscientemente de modo contrário ao devido. Em suma, uma conduta distinta era exigida do causador dos danos. Não há responsabilidade civil subjetiva se afastado esse pressuposto da exigibilidade de comportamento diverso.

Assim sendo, segundo a parte que acolhe a responsabilidade objetiva em relação aos danos sofridos, pelo meio ambiente, é o poluidor que é obrigado a reparar os danos ambientais e a terceiros que venham a ser afetados por essa atividade danosa.

Quando tratamos de um tipo de gênero adaptamos os conceitos impostos nesta para outra forma que o tipo não se afaste de seu gênero, descaracterizando, no caso do direito. $\mathrm{Na}$ responsabilidade civil ambiental, como no direito ambiental devemos sempre tratar esta como

\footnotetext{
${ }^{7}$ CAVALIERI FILHO, Sérgio. Programa de Responsabilidade Civil. 6.ed. São Paulo: Malheiros, 2005.p. 197.
} 
gênero do direito civil, como meio de proteção para remediação de atos prejudiciais aos bens ambientais.

Deste modo, se tivermos no inicio a culpa como um elemento principal da responsabilização civil terá a inclusão como norma de exceção, da responsabilidade objetiva.

Alguns doutrinadores acreditam que possa existir tanto no direito privado como no direito público, um princípio de pelo qual a licitude da atividade não exclui o dever de indenizar.

No entanto, à semelhança do que acontece no âmbito da responsabilidade objetiva do Estado é que, no Direito positivo, a responsabilidade objetiva por danos ambientais é o do risco criado, no qual, acolhe as excludentes da culpada vítima ou terceiros, na força maior do caso fortuito e não a do conhecido risco integral que inadmite excludentes, nos termos do artigo 14, $\$ 1^{\circ}$ da Lei $n^{\circ} 6.938 / 81$ (Lei que dispõe da Política Nacional do Meio Ambiente), que somente empenha a responsabilidade alguém por danos ambientais, quando ficar comprovada a ação efetiva, ou seja, o ato praticado por esse alguém, direta ou indiretamente na ocorrência do dano.

Em regra, a responsabilidade civil decorre da culpa, porém, quando se tratar de matéria ambiental basta o nexo de causalidade entre o ato e o dano para que haja a responsabilidade civil do causador do prejuízo, ainda que ele decorra de ato lícito ou de risco.

Desta maneira, o causador de danos ao meio ambiente assume riscos de sua atividade arcando com prejuízos em matéria ambiental, seja em face de pessoas com que se relacionou ou até mesmo terceiros nesta relação.

Portanto, fica expresso na Lei $\mathrm{n}^{\circ} 6.938 / 81$ é que a responsabilidade pelo dano ambiental é fundada na teoria do risco criado e não na teoria do risco integral.

\section{O MEIO AMBIENTE}

O meio ambiente deve ser abrangido não apenas como meio ambiente da natureza, mas por um complexo de ambientes que interagem entre si, como o meio ambiente do trabalho, 0 meio ambiente cultural, o meio ambiente rural, o meio ambiente urbano, dentre tantos outros. Com isso, verifica-se que o conceito de meio ambiente inclui tudo o que existe de vital em um determinado espaço. 0 meio ambiente é a interação de um conjunto que reúne os elementos 
naturais, elementos artificiais e os elementos culturais, propiciem o desenvolvimento equilibrado na vida.

No entanto, o ser humano faz parte desse conjunto e deve desta forma, agir de maneira equilibrada para dar continuidade às relações sociais. Desta, surge a existência de uma tutela jurídica para que não seja comprometido esse ciclo natural, pois, se o fizer, este dano será irreversível.

Os prejuízos que ocorrem na conservação da natureza, considerados como problemas por muitos doutrinadores, devem ser observados a partir das ocorrências da urbanização, por que, decorre desta a alta concentração populacional num determinado território. Em virtude desse crescimento, há a precisão de ordená-lo, com a implementação de saneamento básico, sistema de abastecimento e também a construção de casas, atividades estas, que geram uma imensa degradação ambiental que pode acarretar riscos a sobrevivência do próprio grupo.

\section{DANO E DANO AMBIENTAL}

A responsabilidade civil somente poderá ser concebida quando houver algum dano efetivamente ocorrido. Não está apreciada a indenização, ou seja, tornar íntegro aquele ato ou omissão que não gerou na esfera jurídica do sujeito hipoteticamente lesionado. No entanto, o entendimento e a avaliação do que venha a ser dano é de importância substancial para a compreensão daquilo que venha a ser um dano ambiental.

0 dano representa o terceiro elemento da responsabilidade civil, juntamente com o nexo causal e a imputabilidade, que neste ponto se diferencia da responsabilidade penal, sendo que nesta penaliza o a tentativa, o que no direito civil não ocorre com os mesmos efeitos, caso não tenha como consequência um dano patrimonial.

Uma concepção comum aos conceitos de dano é a perda, o entendimento de haver e após um determinado ato deixar de haver algo, ou até mesmo, uma alteração no estado em que este algo se encontrava.

Dano consiste no prejuízo suportado. Pode ser individual ou coletivo, moral ou material, econômico ou não econômico. O conhecimento de dano sempre foi objeto de muita controvérsia. Na noção de dano está sempre presente a noção de prejuízo. 0 dano sem dúvida, o grande vilão da responsabilidade civil, pois, não haveria o que se falar em indenização, nem ressarcimento, se não houvesse o dano. Pode haver responsabilidade sem a culpa de alguém, mas em hipótese alguma pode haver responsabilidade sem o dano. Tanto é assim que, sem dano, 
não haverá o que reparar, ainda que a conduta tenha sido dolosa ou culposa. Se um motorista, mesmo avançando o sinal, não atropela ninguém, nem bate em outro veículo; se o prédio desmorona por falta de conservação do proprietário, mas não atinge ninguém, não haverá oque indenizar.

Portanto, um ato ilícito nunca será aquilo que os penalistas chamam de crime de mera conduta; será sempre um delito material, com a consequência de dano. Sem dano pode haver a responsabilidade penal, mas não haverá a responsabilidade civil. $E$, se a vítima não sofreu nenhum prejuízo, a toda evidência, não haverá o que ressarcir. Daí a afirmação de todos os autores, de que o dano é não somente o fato constitutivo, mas, também, determinante do dever de indenizar.

À existência de dano é condição essencial para a responsabilidade civil. Se quem busca a responsabilização não sofreu dano de nenhuma espécie, mas somente alguns desconfortos ou riscos não terão a princípio, direito a nenhum tipo de indenização.

Bens materiais poderiam ser apreciados os bens nomeados nas inúmeras legislações que elegem, por exemplo, a fauna ictiológica que está elencada no Decreto Legislativo 45/68 que recepcionou a convenção de Genebra de 1958 e trata da proteção de peixes.

Desta forma, mesmo agregando diversos elementos em busca de um conceito de dano ambiental, ele se tornará em algum momento insuficiente, tendo em vista a complexidade da problemática da análise de outras disciplinas sobre a questão. No entanto, podemos somente gerar responsabilidade quando for possível atrelar estes dois elementos, sob pena de, não fazendo, além de obrigar pessoa errada a indenizar, praticar a expropriação. Os abordes de segurança jurídica estão justamente quando é possível, através do processo legal, baseado na falha identificada na pessoa do faltoso, impor-lhe o dever de indenizar.

\section{CONCLUSÃO}

Por tudo, pode-se concluir que as normas ambientais não se encontram coligidas e num primeiro momento, pode parecer que há uma grande dificuldade na sua compreensão e aplicação.

No entanto, a complexidade de um sistema normativo é solucionada pela hermenêutica, que independe da codificação ou não destas normas, pois, se a Constituição é a lei maior, as demais normas organicamente serão compatíveis. Cabe, ao ser humano como sujeito transformador dos bens naturais, a responsabilidade de protegê-los, para garantir sua própria 
sobrevivência, no qual, deve-se ressaltar ser primordial a sobrevivência de outros seres, já que no meio ambiente todos fazem parte de um mesmo conjunto, interagem num mesmo meio e no qual, não existe vida humana sem vida vegetal, vida animal etc.

Eis, neste caso, a importância de existirem leis de proteção jurídica ao meio ambiente por tratar-se de direito à vida, um dos principais direitos elencados no direito fundamental disposto na Carta Magna.

Acredita-se, que é indispensável à conscientização da humanidade e a criação de normas específicas, com punições rigorosas para punir aquele que cometer qualquer tipo de crime contra o meio ambiente. Precisa-se também, de uma fiscalização adequada e organizada, no qual, toda a humanidade colabore, para que os culpados sejam obrigados a indenizar e desta maneira, consiga-se o equilíbrio do meio ambiente. Neste sentido, a humanidade tem papel essencial ante a responsabilidade de preservação ambiental, em concordância com o desenvolvimento fundamentado num planeta sustentável, que venha usar de maneira racional e consciente dos bens naturais para que futuras gerações venham usufruir de um meio ambiente equilibrado.

\section{REFERÊNCIAS}

CAVALIERI FILHO, Sérgio. Programa de Responsabilidade Civil. 6.ed. São Paulo: Malheiros, 2005.

DIAS, José de Aguiar. Da Responsabilidade Civil. Rio de Janeiro: Forense, 2006.

DINIZ, Maria Helena. Curso de Direito Civil Brasileiro: Responsabilidade Civil. v. 7, 21. ed. São Paulo: Saraiva, 2009.

JÚNIOR, José Cretella. O Estado e a Obrigação de Indenizar. São Paulo: Saraiva, 1980.

LOPES, Miguel Maria de Serpa. Curso de Direito Civil. v. 5. 2 ed. Rio de Janeiro: Freitas Bastos, 1995.

MONTENEGRO, Antônio Lindbergh. Responsabilidade Civil. 2.ed. Rio de Janeiro: Lumen Juris, 1996.

PEDROTI, Irineu Antônio. Responsabilidade Civil. 2. ed. São Paulo: Universidade de Direito, 1995.

Recebido em: 11.09.2012 / Aprovado em: 01.11.2012 